\title{
Interventional Spine and Pain Procedure Credentialing: Guidelines from the American Society of Pain \& Neuroscience
}

\author{
Ramana K Naidu (D' \\ Rahul Chaturvedi (iD) ${ }^{2}$ \\ Alyson M Engle ${ }^{3}$ \\ Pankaj Mehta ${ }^{4}$ \\ Brian Su' \\ Krishnan Chakravarthy ${ }^{5}$ \\ Kasra Amirdelfan ${ }^{6}$ \\ Jeffrey Henn ${ }^{7}$ \\ Dawood Sayed (1D ${ }^{8}$ \\ Jay Grider 9 \\ Timothy Deer $\mathbb{D D}^{3}$ \\ 'California Orthopedics \& Spine, \\ Larkspur, CA, USA; ${ }^{2}$ School of Medicine, \\ University of California - San Diego, San \\ Diego, CA, USA; ${ }^{3}$ The Spine \& Nerve \\ Centers of the Virginias, Charleston, WV, \\ USA; ${ }^{4}$ Pain Specialists of America, Killeen, \\ TX, USA; ${ }^{5}$ Department of \\ Anesthesiology, University of California - \\ San Diego, San Diego, CA, USA; \\ 'Integrated Pain Management, Walnut \\ Creek, CA, USA; ${ }^{7}$ Joint Implant Surgeons \\ of Florida, Fort Myers, FL, USA; \\ ${ }^{8}$ Department of Anesthesiology, \\ University of Kansas Medical Center, \\ Kansas City, KS, USA; ${ }^{9}$ Department of \\ Anesthesiology, University of Kentucky, \\ Lexington, KY, USA
}

Correspondence: Ramana K Naidu Email ramonaidu@me.com
Background: The discipline of interventional pain management has changed significantly over the past decade with an expected greater evolution in the next decade. Not only have the number of procedures increased, some of the procedures that were created for spine surgeons are becoming more facile in the hands of the interventional pain physician. Such change has outpaced academic institutions, societies, and boards. When a pain physician is in the credentialing process for novel procedure privileges, it can leave the healthcare system in a challenging situation with little to base their decision upon.

Methods: This paper was developed by a consensus working group from the American Society of Pain and Neuroscience from various disciplines. The goal was to develop processes and resources to aid in the credentialing process.

Results: These guidelines from the American Society of Pain and Neuroscience provide background information to help facilities create a process to appropriately credential physicians on novel procedures. They are not intended to serve as a standard or legal precedent. Conclusion: This paper serves as a guide for facilities to credential physicians on novel procedures.

Keywords: interventional pain management, interventional spine care, credentialing, guidelines

\section{Introduction}

The discipline of interventional pain management and interventional spine care is continuously evolving, resulting in innovations in technology and expansion of indications each year. Many of these procedures compete and overlap with several specialties in medicine.

Academic institutions often responsible for training residents and fellows are sometimes unable to keep up with the introduction of many of these novel and evidence-based procedures for several reasons. Thus, when community hospitals, non-academic healthcare enterprises, and ambulatory surgery centers (ASCs) are faced with credentialing for physicians to perform these unique procedures, there is little to base decisions on besides information about the physician, and information about the procedure.

This manuscript serves to help both facilities and physicians maintain a high standard of care in interventional spine and pain management for the sake of the discipline and for our patients. The American Society of Pain and Neuroscience, a society leading in providing evidence and education about novel interventional 
pain procedures has learned from its membership that there is a need to have guidelines to help both physicians and healthcare facilities maintain safe implementation of these therapies.

\section{Methods}

The executive leadership of the American Society of Pain and Neuroscience developed a consensus working group consisting of both interventional pain physicians and spine surgeons to create guidelines. The sections were divided based on the expertise of each individual physician. The lead author created key questions regarding the history and evolution of interventional pain management, the role of regulatory bodies and societies, education, safety data monitoring and the future of interventional pain procedures.

\section{What is Interventional Pain Management and Interventional Spine Care? How is It Different from Pain Medicine?}

Pain medicine is a heterogenous field of medicine. Although its origins parallel the birth of anesthesiology, aspects of the field have been fortified by other disciplines including surgery, physical medicine and rehabilitation, neurology, psychiatry, internal medicine, family practice, pediatrics, emergency medicine, and radiology. To the non-pain physician or patient, the field is confusing. For this reason, it is important to understand the background, practice philosophy, and goals of physicians who are a part of this wondrous field.

Pain physicians may choose to be comprehensive, though not specialized, or may be focused on a certain aspect of pain medicine. The ideal model, the interdisciplinary clinic, where there are several disparate experts working cohesively, invented at the University of Washington by Dr. John Bonica in the 1960s, is unfortunately cost-prohibitive in today's healthcare system. Some larger systems, academic, Veteran's Affairs, or otherwise, may mimic or take parts of the interdisciplinary/transdisciplinary model for care.

Within any comprehensive entity, there are five distinct modalities to pain care (in no particular order): rehabilitation, complementary and integrative approaches, pain psychology, pharmacologic (medications), and interventional/ surgical therapies. The allure of interventional pain modalities is that they can provide robust results that are sustained. While costs can be high up front, if they can maintain long-term benefit, the costs will be justified. Because of its rapid evolution, Interventional Pain Management (IPM) is one subset of pain medicine that requires fostering and care of the sub-specialty- credentialing is one aspect of this.

The United States continues to be the largest medical device market in the world. It is estimated that $40 \%$ of the device market or $\$ 156$ Billion was utilized in the US in 2017. This market is expected to grow to greater than $\$ 208$ Billion by 2023. The medical device market is also one of the key American exports of approximately $\$ 45$ billion per year to the rest of the world.

Industry not only plays a key role in bringing innovations to market, it also has the moral and professional obligation to appropriately train physicians and surgeons on patient selection, surgical technique, complications and their management. As the medical device industry continues to grow, a standardized approach to provide uniform training for the surgeons will need to be better defined. The key opinion leaders in each specialty will need to work closely with industry partners to better define all aspects of such an endeavors for the present and well into the future. ${ }^{15,16}$ Three tenets to consider for the rollout of any new technology:

- Obtain the highest level of evidence on safety, appropriateness, costs, and effectiveness of any particular novel device. It is incumbent upon industry and physicians to understand these data and their limitations.

- Train surgeons/proceduralists on diagnosis, patient selection, surgical technique, management of complications, and costs.

- Engage in continuous quality improvement by providing proctor supervision, and transparent data collection, to optimize outcomes.

\section{What Has Been the History and Evolution of Interventional Pain Management and Interventional Spine Care?}

The field of interventional pain management has documented origins from the late 19th-century. In 2003, in the United States, it gained its distinction from the Center for Medicare/Medicaid Services (CMS) with a distinct taxonomy (-09) of medical specialization. In the 1990s and 2000s, significant growth in epidural steroid injections and sacroiliac joint injections took place. In the 2010s, 
there was significant growth in radiofrequency ablation and neurostimulation procedures. We project continued growth in all of these interventions, as well as novel minimally invasive spine approaches and peripheral nerve stimulation. While some historical procedures may have questionable relevance, just as we have seen with surgical procedures, the future is dependent on evidencebased and cost-effective care. Sustainable interventions have the potential to obviate the need for continued care as seen with medications, rehabilitation/physical therapy, psychological and complementary/integrative care. When a pain generator can be intervened upon in a safe, appropriate, and effective manner, therein lies the argument for interventional pain management.

\section{What is the "Scope of Practice" of Pain Management?}

The Joint Commission (TJC), formerly known as the Joint Commission on Accreditation of Healthcare Organizations (JCAHO), is a global driver of quality improvement and patient safety in healthcare. ${ }^{1}$ In pain medicine, the Joint Commission has advised the following:

First, the organization must have a leader or leadership team that is responsible for pain management, opioid prescribing, and development as well as performance monitoring for on-going quality improvement. This standard was developed out of the National Academy of Medicine and AHRQ Safety Program for Ambulatory Surgery. Second, TJC delineates criteria for the provision of care, treatment and services in pain management. This is where interventional approaches can be utilized to reduce length-of-stay or reliance on controlled substances. Referrals to clinical experts may be implemented if more extensive assessment or treatment is required. Some examples include pediatric referrals, complex pain management, chronic nonmalignant pain disorders or advanced perioperative needs due to opioid tolerance. The third category of TJC standards for pain assessment and management in the ambulatory setting focus on performance improvement. Guidelines and regulatory policies emphasize cautious opioid prescribing for both acute and chronic pain. ${ }^{2,3}$

Unfortunately, the current TJC standards provide credentialing criteria that fail to address specific expectations when credentialing the interventional pain medicine specialist for advanced procedures. ${ }^{4}$

However, in July 2021, TJC in collaboration with several societies will offer Advanced Certification for
Spine Surgery (ACSS). The goal is to improve quality and safety for spine surgery patients. Advanced interventional and spine procedures are paramount to achieving the goals set forth by TJC.

\section{What is the Role of the State Medical Board?}

The role of state medical boards is sometimes misunderstood in the larger context of physician practice and certification. The primary function of state medical board is to ensure a minimum competency to qualify for a license to practice medicine in a given state. While these regulations vary slightly based upon the state, in general the qualifications will include as a minimum, passage of a medical licensing examination and a requisite amount of graduate medical education (one to two years minimum depending on the state). This will qualify as the minimum to practice medicine in that state but does not outline the ability to practice specialty or sub-specialty medicine. The systems of state medical boards rely heavily upon facilities and physician practices to determine competency to practice within that hospital, ambulatory surgery center or practice location. With the recent opioid epidemic many state medical societies were commissioned to establish minimum standards to practice pain medicine and interventional pain medicine within their jurisdictions. This mandate was usually within the mission of protection of the public good but was an awkward fit for most medical boards. The role of the medical board is clear on both ends of the mission spectrum, namely basic licensure of physicians and physician assistants one end and physician conduct that endangers patients being the other extreme. Medical boards typically rely upon professional medical societies and their boards to determine competency within a specific medical discipline and as such the role of these professional societies is paramount in ensuring fitness to practice. As such, the professional society and sub-specialty board credentialing process is of great interest to many state medical boards.

\section{What is the Typical Credentialing Process in the United States?}

Credentialing is the process of assessing the qualifications of healthcare providers to operate in a certain capacity and standardize their scope of practice to a large extent. Box 1 outlines the standard accepted criteria used when credentialing providers for medical staff appointments. 
Box I Standard Objective Criteria Used in Considering Healthcare Providers for a Medical Staff Appointment ${ }^{6}$

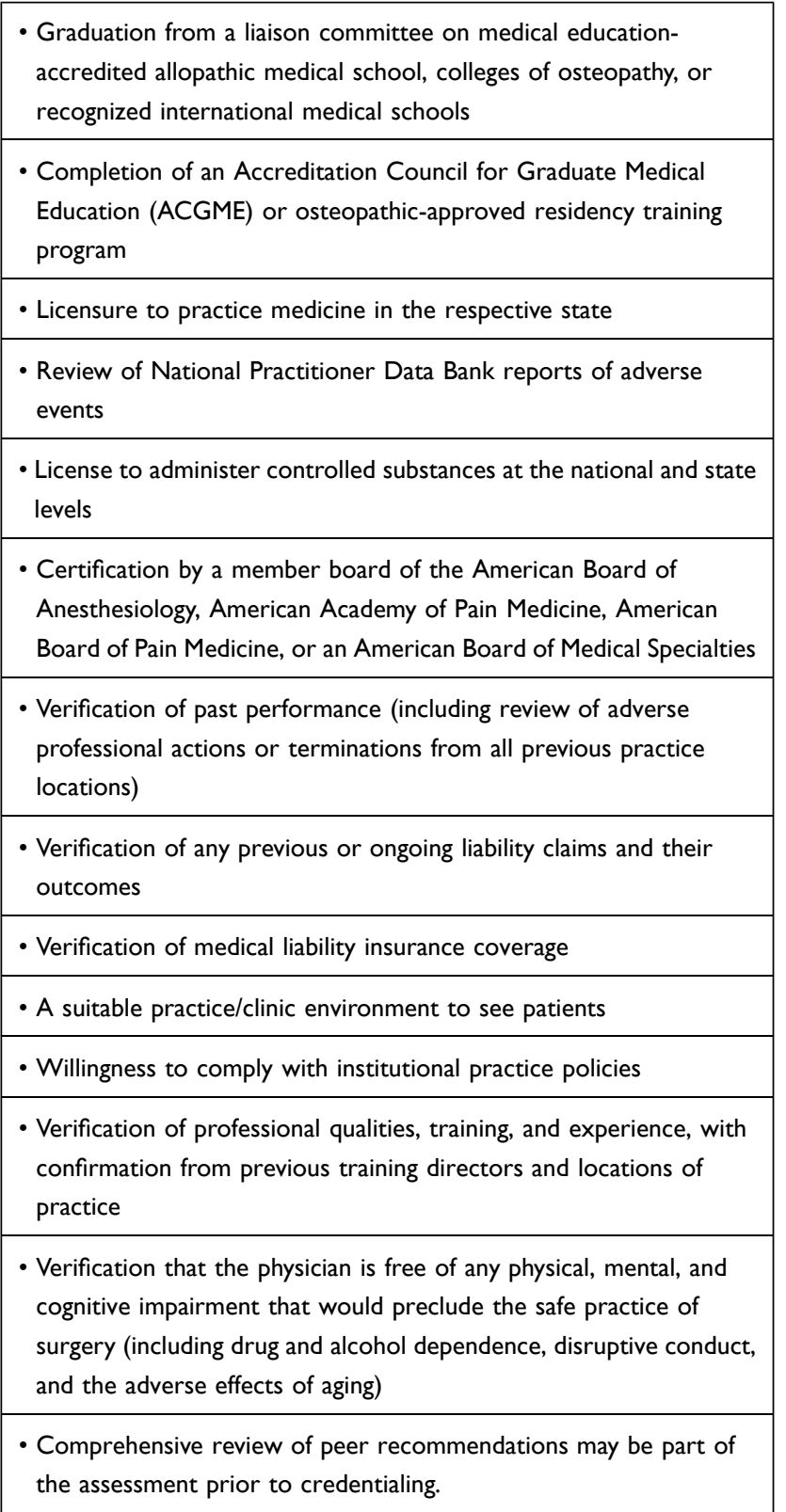

Every physician in the United States is required to be licensed in order to see and manage patients-however, they do not need to be certified in order to practice medicine. Licensure is provided to physicians by their respective state medical board. The certification process, not licensing, is governed by medical boards and not the state board (see below for examples of these medical boards). Maintaining certification through a medical board is indicative of physicians' commitment to a lifelong desire to continue learning and update their medical knowledge as science progresses throughout the years. In order to acquire initial certification, physicians must finish four year of premedical education, earn a medical degree from a certified school, complete three to seven years of residency training accredited by the ACGME, provide attestation letters from a program director from their residency, and obtain an unrestricted medical license to practice in the United States. Additionally, physicians must complete all examinations for their respective medical boards, which is constantly updated to reflect the most recent advances in medical science. Finally, various parameters are required to maintain certification-professionalism, medical knowledge, continuing to take updated board exams at specific time intervals, etc. This medical board certification process ensures that physicians in their respective fields are upholding their oath to provide the best possible care for their patients, and maintain the knowledge required to deliver the best possible care.

\section{What are the US Medical Boards Integral to Board-Certification in Pain Medicine and Interventional Pain Management?}

For interventional spine and pain procedures, board certification verification may be obtained through the American Board of Anesthesiology (ABA), a member board of the American Board of Medical Specialties (ABMS), American Academy of Pain Medicine (AAPM), American Board of Pain Medicine (ABPM) and American Board of Interventional Pain Physicians (ABIPP). The recognition of these bodies varies based on location and specialty in many cases.

\section{ABA (American Board of Anesthesiology)}

$\mathrm{ABA}^{5}$ offers subspecialty certification in pain medicine along with other multidisciplinary fields in anesthesia such as critical care medicine, sleep medicine and hospice and palliative medicine specialties, all of which are components of a wide multidisciplinary specialty education offered by anesthesia and its primary training curriculum. It is the original board to identify pain medicine as a subspecialty certification in 1993. Qualified ABA diplomates are held to the same passing standard as those from other American Board of Medical Specialties. The certification involves a test which is specifically designed to evaluate the practicing physicians' knowledge and clinical judgment in pain medicine. Individuals who pursue interventional pain medicine via the ABA end up with doubleboard certification in anesthesiology and pain medicine. 


\section{AAPM (American Academy of Pain Medicine)}

$\mathrm{AAPM}^{5}$ offers Accreditation with Commendation to providers whom have demonstrated compliance with specific Accreditation Criteria to achieve commendation. The award is provided through AAPM by the Accreditation Council for Continuing Medical Education (ACCME); it allows providers to strategically partner with healthcare systems to implement education strategies. The strategies focus on removing and overcoming barriers to physician change while implementing CME with the goal to improve professional practices, update best practices, and generate meaningful outcomes. There is no specific examination for board certification through the AAPM.

\section{ABPM (American Board of Pain Medicine)}

$\mathrm{ABPM}^{3}$ administers a psychometrically developed and practice-related examination for a physician who has completed a formal training in Pain Management to qualified candidates. Physicians successfully complete the ABPM credentialing process and examination are issued certificates as specialists in the field of Pain Medicine and are designated as Diplomates of the American Board of Pain Medicine. Once board certified the information is available to the public, healthcare regulatory bodies and healthcare facilities. ABPM points out that no certification program can guarantee competence given the rapid changes in medical knowledge and the examination cannot always reflect the most current state of the art practices. This statement is congruent with the field advancements in pain management at present.

\section{ABIPP (The American Board of Interventional Pain Physicians)}

$\mathrm{ABIPP}^{6}$ is a Specialty Board of the American Society of Interventional Pain Physicians providing certification. ABIPP has established certification programs with the goal of improving patient care. ${ }^{9}$ The certification process distinguishes accepted levels of knowledge and expertise in the interventional pain management profession. Physicians must qualify before becoming certified by the ABIPP. ABIPP Certification is recognized in many states with other states in progress. The ABIPP provides certification in the areas of interventional pain management, fluoroscopic interpretation and radiological safety, regenerative medicine, controlled substance management, coding, compliance and practice management.

A physician who is board-certified by an educational board has been credentialled to have met a certain standard of core competencies which fulfill the required training milestones. These core competencies include, but are not limited to quality patient care, practice-based learning and improvement, patient care and procedural skills, systemsbased practice, medical knowledge, interpersonal and communication skills, and professionalism.

Privileging a provider defines the specific interventional procedures and disease conditions that the provider is approved to manage and perform at a health organization. There are substantial differences with respect to privileging practices between organizations and specialties. For example, general surgery includes very broad criteria for privileging, whereas performing specific procedures may include a detailed list of criteria. In general, each organization's needs guide the privileging process. However, the organization's interventional spine and pain leadership at the organization should take the initiative in developing these criteria.

Interventional pain physicians practice a range of procedures from minimally invasive injections to surgical implantations. One recommendation is to define core, intermediate, and advanced privileges, because advanced or complex procedures are often associated with a higher risk of adverse events and require a specific skill set and supportive services, infrastructure, and resources. (See Box 2). The American Society of Pain and Neuroscience has created a table to aid in credentialing (Table 1).

Experience in patient management, basic and advanced procedures vary widely among pain medicine fellowship programs and graduates of those programs. The wide range of competence among initial independent practitioners brings a challenge to the initial privileging review process. As a result, careful examination of candidates' case logs in residency and fellowship should be considered along with references from providers experienced in each of the requested procedures.

More recently, concerns surrounding insufficient training opportunities for independence in residency and fellowship have highlighted the variability in experience among graduates and the need for scrutiny of the early stage-independent proceduralist transitioning to independent practice. ${ }^{6}$ Organizations may acknowledge this liability by granting provisional privileges for a period. The provisional period should include focused professional practice evaluations performed at six-month intervals, and the involvement of a more experienced interventionist or surgeon verifying the new physician's readiness to perform said procedures. For problematic events identified in 
Box 2 Recommended Guidelines for Incorporating Advanced Procedures into the Standard Objective Criteria for Credentialing and Privileging

\begin{tabular}{|l|}
\hline - Graduation from a liaison committee on medical education- \\
accredited allopathic medical school, colleges of osteopathy, or \\
recognized international medical schools \\
\hline - Completion of an Accreditation Council for Graduate Medical \\
Education (ACGME) or osteopathic-approved residency training \\
program
\end{tabular}

- Verification that the physician is free of any physical, mental, and cognitive impairment that would preclude the safe practice of surgery (including drug and alcohol dependence, disruptive conduct, and the adverse effects of aging)

- Comprehensive review of experienced provider recommendations for each advanced procedure

- Case logs from residency, fellowship, and proctored cases

- Focused professional practice evaluations on requested cases

- Patient outcomes following interventions during the provisional period, including multidimensional benchmarks (eg patient satisfaction, adverse effects, safety profile, efficacy of therapy, et cetera).

these six-month evaluations, the experienced physician(s) should provide constructive feedback, counseling, and mentoring. ${ }^{6}$
Some options for credentialing and privileging on advanced interventional pain procedures, include procedural training with didactics and hands-on practice. After this training, which is typically industry-sponsored, it is imperative to require a first supervised, then proctored practice of the procedure.

The number of cases that must be performed to maintain existing privileges is also an area of active discussion, but no absolute numbers exist. Proctors should observe the proceduralist in the operating room and offer unbiased opinions regarding whether a surgeon is technically competent, recognizing that this is only one component of the privileging process.

\section{How Should a Facility Lead the Credentialing Process?}

The credentials committee should have a document that outlines its governance, role, and responsibilities, including an organizational chart and composition. This committee's authority, leadership, and membership should address the organization's specific needs and have adequate surgical and interventional expertise to make appropriate judgments and decisions based on a thorough understanding of the present operative environment. Core functions should include oversight of credentialing, privileging, ongoing professional practice evaluations, constructive feedback, enhanced training and mentorship. Each of the above activities should be accompanied with specific criteria that is based on validated, evidence-based, risk-adjusted data. Box 3 can serve as a template for procedural review for the committee.

\section{What are the Ways and Means by Which Physicians Receive Training and Education on Novel Interventional Procedures? \\ Academic Institutions}

The fundamental understanding of most surgical and pain medicine procedures occur during residency and fellowship training. To assess whether a physician is adequately prepared to deliver efficacious pain medicine and surgical services to patients, practices must understand the breadth and detail that each academic institution provides.

In a study that surveyed thirty-nine residency programs from physical medicine and rehabilitation (PM\&R), residents were shown to have moderate exposure to basic interventions such as ultrasound-guided knee injections and lumbar epidural injections. However, there was great 
Table I ASPN Hospital Delineation of Pain Privileges

\begin{tabular}{|c|c|c|c|}
\hline \multicolumn{4}{|c|}{ Prerequisites for Pain Management } \\
\hline Pain Management & $\begin{array}{l}\text { Constitutes a medical trans-disciplinary specialty with five modalities including } \\
\text { interventional, pharmacologic, complementary and integrative, rehabilitation, } \\
\text { and psychological that provides care for adult and pediatric patients who are } \\
\text { suffering from an unpleasant sensory or emotional experience. }\end{array}$ & & \\
\hline \multicolumn{4}{|c|}{ Prerequisites for Sub-Specialty Pain Management: Interventional Pain Management } \\
\hline $\begin{array}{l}\text { Interventional Pain } \\
\text { Management (IPM) }\end{array}$ & $\begin{array}{l}\text { Is a procedural sub-specialty that requires an understanding of spinal and } \\
\text { peripheral neuroanatomy, radiological safety, surgical safety, and the } \\
\text { management of complications including neural injury. }\end{array}$ & & \\
\hline Requested & Core Pain Management & Approved & $\begin{array}{l}\text { Proctoring } \\
\text { Requirements }\end{array}$ \\
\hline$\square$ & $\begin{array}{l}\text { Diagnosis and management of acute pain: medical, trauma and surgical; chronic } \\
\text { pain; and cancer-related pain } \\
\text { - Performance of focused pain-specific history and physical exam, eg PQRST } \\
\text { - Appropriate use of assessment tools (eg POSS, CPOT, Wong-Baker, SOAPP- } \\
\text { R, ODI, PROMIS-29, etc.) and appropriate diagnostic tests are ordered and } \\
\text { interpreted } \\
\text { - Recognition and management of misuse, abuse and addiction of controlled } \\
\text { substances } \\
\text { - Recognition and management of therapies, side effects, and complications of } \\
\text { pharmacologic agents used in the management of pain } \\
\text { - Expert-level knowledge regarding the use of opioid pharmacokinetics/ } \\
\text { pharmacodynamics, and the risk to the individual and society. } \\
\text { - Expert-level knowledge regarding the use of anesthetic infusions such as } \\
\text { ketamine and lidocaine, pharmacokinetics/pharmacodynamics, and the risk to } \\
\text { the individual. } \\
\text { - When to consult and refer to physical therapy, occupational therapy and } \\
\text { rehabilitative services. } \\
\text { - When to consult with complementary and integrative services } \\
\text { - When to consult with Psychiatric Services } \\
\text { - Superficial electrical stimulation techniques (eg, transcutaneous electrical } \\
\text { neural stimulation) }\end{array}$ & $\square$ & Minimum of 3 cases \\
\hline$\square$ & Myofascial/Trigger point injections & $\square$ & \\
\hline \multicolumn{4}{|c|}{ Pain Management Tier 2 Privileges } \\
\hline Experience & $\begin{array}{l}\text { In addition to core pain management requirements above, for pain } \\
\text { management level } 2 \text { procedures the practitioner must be able to supply } \\
\text { evidence of having performed } 50 \text { of any level } 2 \text { procedures in the past two } \\
\text { years. This may include post-graduate training case log. This evidence must also } \\
\text { include at least } 15 \text { procedures within the individual Group requested. }\end{array}$ & & \\
\hline Requested & Interventional Pain Management Intermediate Procedures & Approved & Proctoring \\
\hline$\square$ & $\begin{array}{l}\text { Single shot peripheral regional anesthesia (eg femoral, saphenous, } \\
\text { suprascapular, intercostal, occipital nerves) under imaging guidance (U/S or } \\
\text { fluoroscopy) }\end{array}$ & $\square$ & $\begin{array}{l}\text { Minimum of } 3 \text { cases of any } \\
\text { Tier } 2 \text { Group I procedures }\end{array}$ \\
\hline$\square$ & $\begin{array}{l}\text { Single shot peripheral regional anesthesia (eg femoral, saphenous, } \\
\text { suprascapular, intercostal, occipital nerves) under imaging guidance (U/S or } \\
\text { fluoroscopy) }\end{array}$ & $\square$ & $\begin{array}{l}\text { Minimum of } 3 \text { cases of any } \\
\text { Tier } 2 \text { Group I procedures }\end{array}$ \\
\hline
\end{tabular}

(Continued) 
Table I (Continued).

\begin{tabular}{|c|c|c|c|}
\hline$\square$ & Injection of MAJOR joints, including sacroiliac, hip, knee, shoulder, etc. & $\square$ & \\
\hline$\square$ & $\begin{array}{l}\text { Injection of bursae, including greater trochanteric bursa, ischial tuberosity } \\
\text { bursa, etc. }\end{array}$ & $\square$ & \\
\hline$\square$ & $\begin{array}{l}\text { Radiofrequency ablation (RFA)/Rhizotomy/Neurolysis and the Diagnostic } \\
\text { Blockade of articulating branches for major joints including sacroiliac joint, } \\
\text { shoulder, hip, and knee (evidence of } 3 \text { prior cases required)* }\end{array}$ & $\square$ & \\
\hline$\square$ & Chemical motor denervation (eg Botox ${ }^{\circledR}$ injection) & $\square$ & \\
\hline$\square$ & $\begin{array}{l}\text { Insertion of indwelling catheters for the use of regional anesthesia (epidural, } \\
\text { continuous spinal, peripheral neural blockade) }\end{array}$ & $\square$ & $\begin{array}{l}\text { Minimum of } 3 \text { cases of any } \\
\text { Tier } 2 \text { Group } 2 \text { procedures }\end{array}$ \\
\hline$\square$ & $\begin{array}{l}\text { Epidural Steroid Injection (interlaminar and/or transforaminal) under } \\
\text { fluoroscopic guidance }\end{array}$ & $\square$ & \\
\hline$\square$ & Epidural adhesiolysis & $\square$ & \\
\hline$\square$ & Facet (zygapophyseal joint) injection under fluoroscopic guidance (C/T/L/S) & $\square$ & \\
\hline$\square$ & $\begin{array}{l}\text { Radiofrequency ablation (RFA)/Rhizotomy/Neurolysis and the Diagnostic } \\
\text { Blockade of spinal medial branches (C/T/L) (evidence of } 3 \text { prior cases required) }\end{array}$ & $\square$ & \\
\hline$\square$ & Intradiscal injection (eg local anesthetics, therapeutics) & $\square$ & \\
\hline$\square$ & Provocation discography & $\square$ & \\
\hline$\square$ & $\begin{array}{l}\text { Sympathetic Blockade: (Stellate Ganglion, Celiac Plexus/Retrocrural Splanchnic, } \\
\text { Superior Hypogastric, Ganglion Impar) }\end{array}$ & $\square$ & \\
\hline \multicolumn{4}{|c|}{ Pain Management Tier 3 Privileges } \\
\hline Experience & $\begin{array}{l}\text { In addition to core pain management requirements above, for pain } \\
\text { management level } 3 \text { procedures the practitioner must be able to supply } \\
\text { evidence of having performed } 5 \text { of any level } 3 \text { procedures in the past two years. }\end{array}$ & & \\
\hline Requested & Interventional Pain Management Advanced Procedures & Approved & Proctoring \\
\hline$\square$ & Spinal Cord (Dorsal Column) Stimulation - percutaneous trial lead placement* & $\square$ & $\begin{array}{l}\text { Minimum of } 3 \text { cases of any } \\
\text { level } 3 \text { procedures }\end{array}$ \\
\hline$\square$ & $\begin{array}{l}\text { Dorsal Root Ganglion Stimulation - percutaneous trial lead placement. *(Must } \\
\text { have completed FDA-mandated training) }\end{array}$ & $\square$ & \\
\hline$\square$ & $\begin{array}{l}\text { Spinal Cord (Dorsal Column or Dorsal Root Ganglion) Stimulation - } \\
\text { implantation and explantation of leads and implantable pulse generator* }\end{array}$ & $\square$ & \\
\hline$\square$ & $\begin{array}{l}\text { Peripheral Nerve Stimulation - percutaneous trial lead placement, } \\
\text { implantation, and explantation of implantable pulse generator* }\end{array}$ & $\square$ & \\
\hline$\square$ & $\begin{array}{l}\text { Percutaneous Peripheral Nerve Stimulation with an External Pulse Generator } \\
\text { (e.g SPR Therapeutics)* }\end{array}$ & $\square$ & \\
\hline$\square$ & $\begin{array}{l}\text { Sympathetic Neurolysis: (Stellate Ganglion, Celiac Plexus/Retrocrural } \\
\text { Splanchnic, Superior Hypogastric, Ganglion Impar) via chemical or thermal } \\
\text { means. }\end{array}$ & $\square$ & \\
\hline$\square$ & Neuraxial Neurolysis including Subarachnoid & $\square$ & \\
\hline$\square$ & Kyphoplasty/Vertebroplasty* & $\square$ & \\
\hline
\end{tabular}

(Continued) 
Table I (Continued).

\begin{tabular}{|l|l|l|l|}
\hline$\square$ & Basivertebral Nerve Radiofrequency Ablation (eg Relievant Intracept)* & $\square$ & \\
\hline$\square$ & $\begin{array}{l}\text { Intrathecal Pumps - percutaneous intrathecal catheter trial placement and } \\
\text { management, implantation and explantation of intrathecal catheter and infusion } \\
\text { pump* }\end{array}$ & $\square$ & \\
\hline$\square$ & Percutaneous discectomy/nucleoplasty & $\square$ & $\square$ \\
\hline$\square$ & Indirect Lumbar Decompression of the Spine (eg Vertiflex Superion)* & $\square$ & \\
\hline$\square$ & $\begin{array}{l}\text { Posterior Sacroiliac Joint Arthrodesis when implant is placed intra articular and } \\
\text { parallel to the joint without additional fixation (ie no screw/rod construct } \\
\text { across the joint)* }\end{array}$ & $\square$ & \\
\hline$\square$ & Direct Percutaneous Lumbar Decompression of the Spine (eg Vertos MILD)* & $\square$ & \\
\hline
\end{tabular}

Note: *May have prerequisite industry-led training.

variation in terms of the training that the residents received. When $\mathrm{PM} \& \mathrm{R}$ program directors were asked to assess the level of preparedness of their residents, 33\% reported them to be "fairly prepared" for spine procedures and $20.5 \%$ as "well prepared". ${ }^{10}$ However, $63 \%$ of fellowship directors reported incoming fellows as at the "beginner" level for these procedures. Thus, while some graduating PM\&R residents may have basic skills in certain spinal procedures, private practices must be cautious

Box 3 Best Practice Guidelines for Industry Training of Novel Pain Procedures

\begin{tabular}{l}
-Follow FDA-Directed Mandates on Procedural Training and \\
Education. \\
\hline -Training Course is directed by a Physician with Expertise in the \\
Procedure. \\
\hline $\begin{array}{l}\text {-Trainees are peer selected by physicians, not solely by industry } \\
\text { representatives. }\end{array}$ \\
\hline -Train those with appropriate board certification and ACGME \\
accredited training. \\
\hline -Trainees are vetted for being in current satisfactory practice standing. \\
\hline $\begin{array}{l}\text {-Training be composed of didactic component that includes review of } \\
\text { data, mechanisms, safety, and alternative treatments. }\end{array}$ \\
\hline $\begin{array}{l}\text {-Include Physician Directed Hands-on component with cadaver or } \\
\text { equivalent models. }\end{array}$ \\
\hline $\begin{array}{l}\text {-Trainees should pass post exam assessment of clinical knowledge and } \\
\text { hands-on component. }\end{array}$ \\
\hline $\begin{array}{l}\text {-Trainees with deficiencies should be identified for follow-up training } \\
\text { opportunities prior to implementing procedure/therapy. }\end{array}$ \\
\hline
\end{tabular}

when truly relying on scattered residency training for these procedures. The most data exist for adequate experience comes from anesthesiology training programs. For instance, with respect to regional anesthesia experience, a study including 1631 residents from 129 training programs demonstrated that all residents at the 10th percentile or higher had acquired benchmark levels for spinal, epidural and peripheral nerve blocks. ${ }^{11}$ They also had significant experience in not only epidural, but also facet injections during training.

There is variance in the interventional spectrum of academic centers. For instance, several nerve blocks (eg, stellate ganglion blocks, occipital nerve blocks, and peripheral nerve blocks) are best performed under ultrasound guidance. However, studies from 2014 have shown that less than $50 \%$ of fellowship programs require their trainees to learn ultrasound-guided techniques. Private practices thus may need to rely on comprehensive interviews to make sure that these procedures were covered during a candidates' training. ${ }^{12}$ According to fellowship directors, the primary reason that this technique is not covered is due to it being too time consuming. ${ }^{12}$ Other reasons include differing opinions as to the ultrasoundguided technique's role given the irreplaceability of fluoroscopy. Faculty members conduct most training in academic institutions, which heavily influences how fellows learn various procedures. However, emphasis of training through simulation centers in pain fellowship curriculums can allow pain medicine physicians to become adept at handling challenging patient cases, stressful peri-procedural adverse events, and various emergency algorithm steps. ${ }^{13}$ 
While peripheral nerve blocks and spinal procedures are the core of pain medicine, newer technologies such as spinal cord stimulation (SCS) are emerging technologies that require specific training and expertise. Interestingly, current fellows have been shown to be more likely to have received SCS training as compared to fellows in the past, with around $100 \%$ of fellows being exposed to this technique in current fellowship program. ${ }^{7}$ However, as with many of the procedures described above, significant variability exists with training and exposure. In a recent study, $46 \%$ of fellows expressed concern regarding their SCS training. Around $38.5 \%$ of these fellows noted the volume of cases available to them being the primary issue, while $30.8 \%$ of them noted the lack of a formal curriculum regarding the procedure. ${ }^{7}$ To improve training across fellowship programs, the technique must be incorporated into a formal curriculum.

There is growth in peripheral nerve stimulation, interspinous spacers, minimally invasive lumbar decompression, basivertebral nerve ablation, kyphoplasty and vertebroplasty, minimally invasive SI joint fusion, and minimally invasive interspinous-interlaminar fusion that will require more advanced training beyond industry-funded cadaver courses. Academic training institutions will need to consider ways of certifying these procedures in their fellowship training to prepare fellows upon graduation. Some of these procedures may be restricted by a center's Value Analysis Committee thus harming the education of fellows.

One study created an educational module to verify procedural competency for pain medicine fellows in an objective manner. After receiving standardized training on certain interventional techniques, these physicians were evaluated both at the 3-month and 9-month marks into their training. ${ }^{14}$ All the fellows passed their checklist-based evaluations and improvement was shown between the three-month and ninemonth time points. Additionally, these fellows demonstrated appropriate competency in chart-stimulated oral exams, physical exam maneuvers, and a medical knowledge written test. ${ }^{14}$ The fellows were also evaluated by patients through surveys with excellent results. Formal teaching, milestones, and evaluation are ways to ensure competency among pain medicine specialists and should be emphasized among programs across the country.

\section{Surgical Apprenticeship Model}

Orthopedic and Neurosurgical spine surgeons are trained in spinal surgery during their residency and then typically undergo one year of additional subspecialty fellowship training. The fundamental basis of this training is an apprenticeship model with one or more experts in the field of spinal surgery. This usually begins with the resident/fellow watching an attending perform a specific surgery while acting as their first assistant and then progressively performing more aspects of the case under careful supervision. Depending on the case complexity and potential for complication, this may require several cases before it is appropriate to progress into the role of primary surgeon. Some relatively routine cases, such as a microdiscectomy require less apprenticeship than other more complex cases such as complex instrumented fusions.

This apprenticeship model has worked well for years and has led to the appropriate and safe training of generations of spine surgeons. Of course, in order to be of benefit, the resident/fellow must be exposed to enough number and variety of spinal surgeries, which is overseen by the specialty governing bodies. Beyond comprehensive training, practicing spine surgeons must continue to evolve and master new techniques as the field advances. Some estimate that by 15 years after fellowship training, spine surgeons will use only half of the techniques that they learned in their fellowship. Our rapidly changing field has included such new techniques as minimally invasive fusions, transpsoas lateral approaches, robotic/navigation assisted surgery, and endoscopic surgery. Spine surgeons have typically been able to readily adapt to these techniques because they are ultimately based on fundamentals they learned in their training.

The main challenge in training post-graduate interventional spine and pain management practitioners in minimally invasive procedures (interspinous spacers, spinous process fixation, decompression, spinal cord stimulators and SI fusion, etc.) is that it is may be a significant departure from their current residency and fellowship training. Of course, as their training programs evolve and incorporate these techniques, this will become less of an issue. Furthermore, there is also a crossover benefit from some of these technique to others. For example, a practitioner experienced in spinal cord stimulator placement will already possess skills and experience that will extend to learning other procedures such as SI fusion. As each practitioner navigates this "transition period", the emphasis must be on appropriate training and candid evaluation with the ultimate goal being successful patient outcomes and minimal complications. For interventional spine and pain management physicians to safely perform these procedures, we advocate an apprenticeship model co-managed by industry and physician experts. This 
should include both didactic learning and hands-on training. The didactic session would focus on issues such as patient selection/indications, risks and benefits of the procedure, evidence-based outcomes, and an overview of patient positioning and surgical technique. This should then be followed by small group cadaveric training where an expert would train and oversee the trainee performing the procedure. Based on the trainee's prior experience and aptitude, it may be necessary for some to undergo additional training, including repeat cadaveric training and/or viewing the expert perform the procedure in a livepatient setting. When possible, the expert should then observe the trainee perform their first procedure on one of the trainee's patients at the trainee's hospital or surgery center. This would typically require the expert to obtain temporary privileges at the facility. Credentialing of the physician would then proceed according to the facility's guidelines. This apprenticeship model assures high-quality patient care and provides the optimal pathway for safe and successful training of interventional spine and pain management physicians.

\section{Industry}

Newer advanced procedures in neuromodulation and minimally invasive spine have typically been taught largely through industry or company-directed training programs. The variability in training across the various industry-led courses can be significant as there has been no universally accepted standard. In addition to variability to training, there is typically no set standards for trainee selection and minimal pre-requisites required to undergoing training. Although many industry-led trainings have been successful in the safe and effective implementation of novel pain procedures, standardization of industry training is necessary to ensure the safe and effective teaching of novel interventional pain therapies.

A publication performed by Pak in 2019 surveyed pain fellows and recently graduated fellows with regards to training in neuromodulation. ${ }^{7}$ In this survey, they specifically looked at the impact of industry directed spinal cord stimulator (SCS) training on future practice with regards to implementation of the therapy. Per the survey results, $79.5 \%$ of graduating fellows and $55.4 \%$ of past fellows strongly supported direct training of pain fellows by SCS manufacturers. $^{7}$ Additionally, $77.5 \%$ of graduating fellows and $66.3 \%$ of past fellows responded that they received SCS training in industry directed courses. The results of this study reveal that the majority of recent graduates of pain fellows both support and receive training in industryled SCS courses. Although no similar study has looked at non-SCS novel procedure training, it is safe to assume that results would be similar.

At a minimum, FDA-mandated requirements for industry-led trainings include that education remain consistent with product labeling, therapy is supported by evidence, is not untruthful or misleading, must disclose safety information, and that off-label promotion is prohibited. ${ }^{8}$ Industry has an inherent interest to maintain the highest standards of training and practice in their physicians with the greatest threat being greed. Beyond FDA requirements, Box 3 also summarizes recommended best practice for industryled training programs.

\section{Society Certification}

There are several societies that provide a certificate for specialized training. For example, the World Institute of Pain (WIP) offers a certification in interventional pain and for ultrasound-guided interventional pain procedures. This certificates, Fellow of Interventional Pain Practice (FIPP) and the Certified Interventional Pain Sonologist (CIPS), are based on an examination. Other examples include The North American Neuromodulation Society (NANS) which offers certificates for peripheral nerve stimulation or North American Spine Society (NASS) which offers several courses based on a cadaveric training by experts. Despite such certifications, the certificates may or may not have any direct bearing on credentialing at a particular facility.

\section{What is the Role of Medical Societies in Credentialing?}

The role of societies in credentialing has been debated for many years and has been confusing. The best example in the United States of pain medicine credentialing has been with the American Society of Anesthesiology (ASA), which has been involved with overseeing the majority of physicians practicing pain medicine for the past 70 years. The Committee on Pain Medicine of the ASA has been involved with creating very general guidelines (Ref. pain guidelines from ASA 2011 in Anesthesiology), by providing evidence-based information for providers. However, the ASA has had no particular certification for pain medicine. The same can be said for the credentialing authority for other pain-based societies, such as the American Society of Interventional Pain Physicians (ASIPP) and the American Academy of Pain Medicine (AAPM). As mentioned above, World Institute of Pain (WIP) offers 
a certification for interventional pain and ultrasoundguided procedures. This has been helpful for physicians practicing in countries where there is no formal subspecialty board and has provided an additional level of certification to practitioners who are already board-certified in the United States. Overall, the role of these societies in credentialing has been limited.

Due to the limitations of societies to define credentialing, the American Society of Pain and Neuroscience (ASPN) has determined the need for a credentialing article that can set the standard for proper considerations for credentialing. This is particularly important because the ability of any board to define proper skills or education to establish credentialing once a practitioner is exposed to new interventional techniques is an unreasonable task.

\section{What is the Role of the FDA When It Comes to Credentialing?}

The Food and Drug Administration (FDA) is the ultimate authority in approving new surgical devices and procedures in the United States. This authority was granted to the FDA after congress approved The Medical Device Amendments Act in $1976 .{ }^{17}$ Within the FDA, the Center for Devices and Radiological Health (CDRH) typically oversees the process of scrutiny and approval. There are several pathways a medical device can go through for approval (Figure 1).

The FDA has played a role in mandating specific education about certain procedures. For example, in 2016, the FDA mandated that dorsal root ganglion

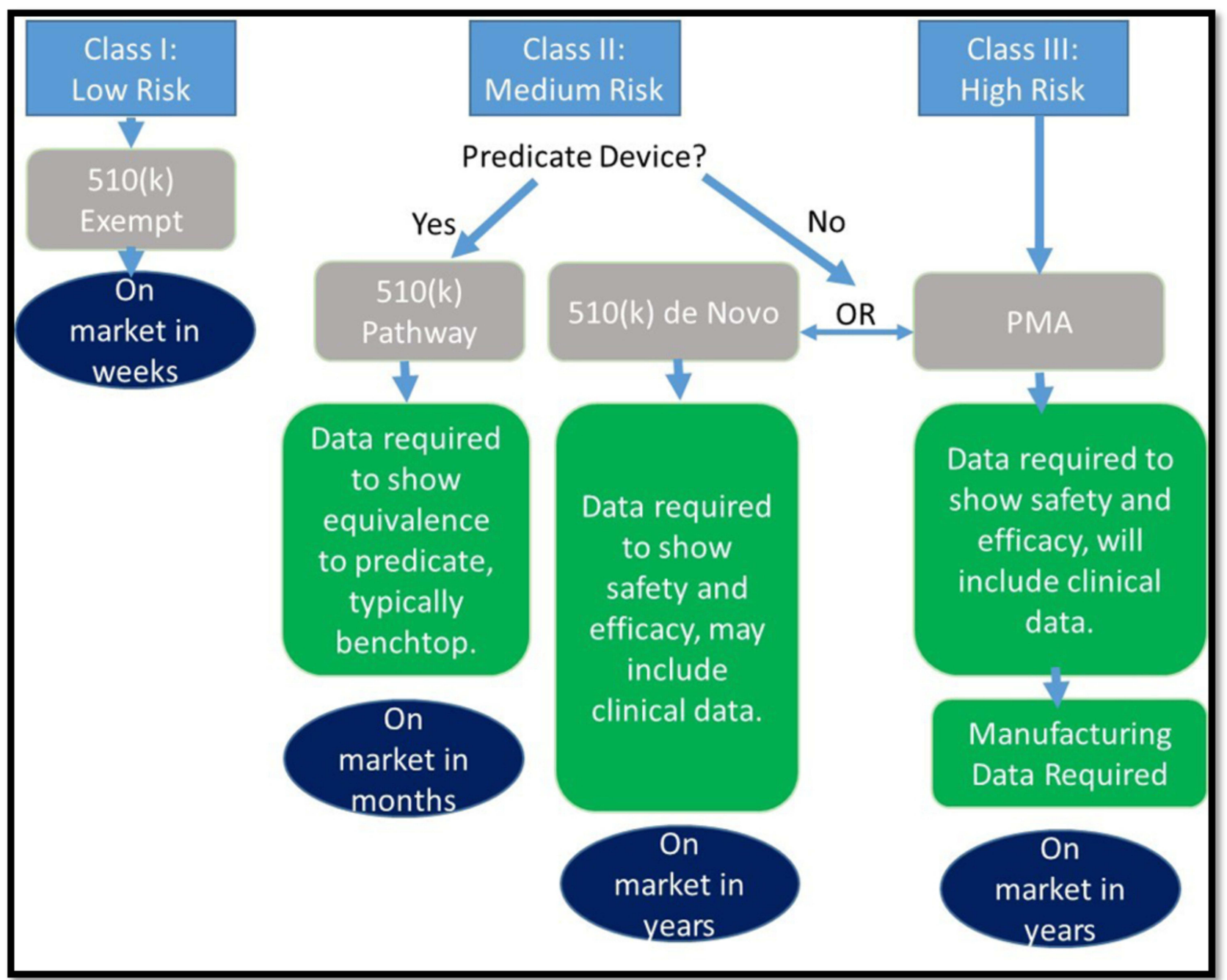

Figure I Flow chart.

Note: Reproduced with permission from Martha Murray JD. An overview of the FDA approval process for devices. American Academy of Orthopaedic Surgeons (AAOS); 2020. Available from: https://www.aaos.org/aaosnow/2020/jul/research/research03/. ${ }^{21}$ 
(DRG) stimulation require advanced training for physicians who would offer this therapy to the patient population labeled for this device. ${ }^{18}$ The FDA analysis of safety and efficacy showed that DRG stimulation was actually safer than the control device (dorsal column SCS), although not to the level of statistical significance. Despite evidence for safety and efficacy from the IDE study (Accurate, Deer/Levy), the FDA determined with the manufacturer that physicians should have both didactic and hands-on training per the labeling prior to use. That requirement appeared to be successful in maintaining safety for the device in the post-market approval phase based on mandated manufacturer data on safety compared to SCS in the real-world setting. ${ }^{19}$

The level of thorough scrutiny and oversight by the FDA is designed to primarily ensure patient safety, as well as optimal outcomes for various indications. All surgical devices, whether new or an improvement of an existing device, will have to enter the market through the above or a variation of the above, channels. In some instances, the FDA may require enhanced training by the manufacturer to ensure the safety of the procedure and its therapy.

\section{What is the Importance of Data and Research on Quality of Care as Part of Credentialing?}

Obtaining data on the safety, effectiveness, and costs of procedures will be one of the most important drivers shaping healthcare in the next several decades. Although a number of interventional procedures come with higher upfront costs, their safety and efficacy have the potential to reduce healthcare utilization and costs over time. Pharmacologics, which may have lower recurrent costs, can result in adverse outcomes over time, such as seen with the American opioid epidemic. Commercial payers which carry beneficiaries from one year to the next, may not be interested in the long-term data and thus may prefer the lower recurrent payment option over the higher upfront cost procedure, thus making access to interventional pain procedures more challenging despite level 1 evidence as seen with indirect lumbar decompression or basivertebral nerve radiofrequency ablation.

In clinical practice, we rely on premarket approval evidence to substantiate the use of a medical device. However, even the best of studies can be biased. The future will depend on reproducibility with post-market approval data collection via continued studies via registry, RCT, or large databases. Utilizing large (RCTs) will be crucial in better understanding the cost utility of certain interventional procedures. Farber et al utilized a large database to study patients with failed back surgery syndrome (FBSS) from 2000 to 2012. ${ }^{20}$ They conducted a longitudinal analysis to understand the cost utility of spinal cord stimulation (SCS) implantation versus conventional management for FBSS patients, and found that although upfront costs are indeed higher for the more interventional approach, there is a decline in cost the year following implant. Specifically, SCS was associated with a cost ratio of 1.74 compared to conventional methods at the time of implantation, but there was a $68 \%$ decrease in cost in the year following implantation compared to conventional methods. While it may seem to patients that the more interventional approach is more costly, data such as these can help show payers and patients the longterm cost and health benefits.

Data collection is not only important regarding the procedure itself (based on CPT), but it has implications for the provider and the healthcare facility as well. The means by which the data is collected, and the variables collected are important. For instance, numerous studies extrapolate information and make conclusions based on the Medical Expenditure Panel Survey (MEPS), a set of large surveys of patients, medical providers and employers on healthcare costs, however, its use is limited. Insurance carriers have ample data on actual healthcare costs for millions of interventional procedures and have the ability to track healthcare costs and quality for individuals over time. However, these data are opaque to stakeholders- industry, hospitals, and physicians all have an interest in knowing their safety and outcomes data. Digital platforms that can facilitate the gathering of quality data with a user-friendly interface regarding outcomes will be paramount. Concerns about patient privacy and physician and center outcomes transparency will be the most controversial issues going forward. If these issues can be managed, such data can shape the practice of these novel procedures and the credentialing process.

\section{Conclusion}

The growth of interventional spine and pain procedures will continue to improve the quality of lives for many Americans. Technology continues to improve due to miniaturization, metallurgy innovation, imaging guidance improvement, and education. With its rapid evolution come several challenges. This paper serves as guidance 
for healthcare systems to review how to credential those performing these unique procedures.

\section{Disclosure}

Dr Ramana K Naidu is a consultant for Abbott, Boston Scientific, Biotronik, Bicycle Health, CereVu, DoctorPlan, ExerAI, KarunaLabs, Medtronic, Nalu, Omnia Medical, PainTEQ, Relievant, SonoSite, SPR Therapeutics, and Vertos, outside the submitted work. Dr Pankaj Mehta is a consultant and/or advisory for Abbott, Boston Scientific, SPR, Corner loc, PainTEQ, and Ethos labs, outside the submitted work. Dr Kasra Amirdelfan is a consultant for Nevro, Medtronic, Boston Scientific, Saluda, Biotronik, Nalu, Presidio, Mesoblast, Vivex, and ENSO. Dr Dawood Sayed reports personal fees from Abbott, Flowonix, Medtronic, Vertos, Nevro, SPR, Merit, PainTeq, SPR, and Neuralace, during the conduct of the study. Dr Timothy Deer reports personal fees from Abbott, Flowonix, Nalu, Stimgenics, SI Bone, Nevro, and Medtronic; grants and/or personal fees for, stock options from Vertos, Axonics, SpineThera, Cornerloc, Ethos, and Painteq; grants from Saluda, Mainstay, Vertiflex, SPR Therapeutic, and Boston Scientific, outside the submitted work; in addition, Dr Timothy Deer is the DRG lead and has a patent pending to Abbott. Dr Krishnan Chakravarthy is a consultant to Medtronic, Bioness, Medincell, PAINTEQ, Vivex Biologics. He has stock options in Aya Bioscience, Higgs Boson Health, Mainstay Medical, Nalu Medical, OSKA Wellness, UMEHEAL. He is a founder of NXTStim, Douleur Therapeutics, Newrom Biomedical, and Accufix Medical. The authors report no other conflicts of interest in this work.

\section{References}

1. Pain Assessment and Management Standards for Ambulatory Care." The Joint Commission. JCAHO. 2019;16(14):1-6.

2. Parchman ML, Von Korff M, Baldwin L-M, et al. Primary care clinic re-design for prescription opioid management. $J$ Am Board Fam Med. 2017;30(1):44-51. doi:10.3122/jabfm.2017.01.160183

3. The Joint Commission. Pain assessment and management standards for ambulatory care. JCAHO. 2019;16(14):1-6.

4. The American Board of Anesthesiology. Pain Medicine Subspeciality Certification Examination. 2020. Available from: https://www.theaba. org/subspecialty\%20certification\%20exams.html. Accessed December, 27, 2020.
5. Midboe AM, Lewis ET, Paik MC, et al. Measurement of adherence to clinical practice guidelines for opioid therapy for chronic pain. Transl Behav Med. 2012;2(1):57-64. doi:10.1007/s13142-011-0104-5

6. The American Board of Anesthesiology. Subspecialty Certification Exams. 2020. Available from: https://theaba.org/subspecialty\%20cer tification\%20exams.html. Accessed October 12, 2020.

7. American Academy of Pain Medicine. Accreditation council for continuing medical education, 2020. Available from: https:// painmed.org/accreditation/. Accessed October 12, 2020.

8. American Board of Pain Medicine. Certification Examination in Pain Medicine; 2021.

9. Competency Certifications Author: American Board of Inteventional Pain Physicians. Available from: https://abipp.org/index.php/compe tency-cerifications/. Accessed October 12, 2020.

10. Statement on Credentialing and Privileging and Volume Performance Issues. American college of surgeons; 2018. Available from: https:// www.facs.org/About-ACS/Statements/111-credentialing. Accessed October 12, 2020.

11. Agarwal S, Cicone C, Chang P. Interventional pain procedures in physical medicine and rehabilitation residencies. Am J Phys Med Rehabil. 2018;97(4):298-303. doi:10.1097/PHM.0000000000000871

12. Neal JM, Gravel Sullivan A, Rosenquist RW, Kopacz DJ. Regional anesthesia and pain medicine. Reg Anesth Pain Med. 2017;42 (4):437-441. doi:10.1097/AAP.0000000000000623

13. Asaad BO, Reinsel RA, DeVeaux E, Moten H, Durkin B. A survey on teaching ultrasound-guided chronic pain procedures in pain medicine fellowship programs. Pain Physician. 2014;17(6):E681-9.

14. Hoelzer BC, Moeschler SM, Seamans DP. Using simulation and standardized patients to teach vital skills to pain medicine fellows. Pain Med. 2015;16(4):680-691. doi:10.1111/pme.12694

15. Pak DJ, Gruber J, Deer T, et al. Spinal cord stimulator education during pain fellowship: unmet training needs and factors that impact future practice. Reg Anesth Pain Med. 2019;44(3):407-414. doi:10.1136/rapm-2018-100065

16. McElroy K, Cuccurullo SJ, Perret-Karimi D, et al. Interventional pain management skills competency in pain medicine fellows. Am J Phys Med Rehabil. 2014;93(8):724-731. doi:10.1097/ PHM.0000000000000142

17. U.S. Food \& Drug Administration. Training and Continuing Education, 2020. Available from: https://www.fda.gov/training-andcontinuing-education. Accessed October 12, 2020.

18. U.S. Food \& Drug Administration. Premarket Approval (PMA), 2016. Available from: https://www.accessdata.fda.gov/scripts/cdrh/ cfdocs/cfPMA/pma.cfm?\%20id=P150004. Accessed October 10, 2020.

19. Deer T, Pope J, Hunter C, et al. Safety analysis of dorsal root ganglion stimulation in the treatment of chronic pain. Neuromodulation. 2020;23(2):239-244. doi:10.1111/ner.12941

20. Farber SH, Han JL, Elsamadicy AA, et al. Long-term cost utility of spinal cord stimulation in patients with failed back surgery syndrome. Pain Physician. 2017;20(6):E797-E805.

21. Martha Murray JD. An overview of the FDA approval process for devices. American Academy of Orthopaedic Surgeons (AAOS); 2020. Available from: https://www.aaos.org/aaosnow/2020/jul/ research/research03/. Accessed October 12, 2020. 


\section{Publish your work in this journal}

The Journal of Pain Research is an international, peer reviewed, open access, online journal that welcomes laboratory and clinical findings in the fields of pain research and the prevention and management of pain Original research, reviews, symposium reports, hypothesis formation and commentaries are all considered for publication. The manuscript management system is completely online and includes a very quick and fair peer-review system, which is all easy to use. Visit http:// www.dovepress.com/testimonials.php to read real quotes from published authors.

Submit your manuscript here: https://www.dovepress.com/journal-of-pain-research-journal 